\title{
MUSEU DA EDUCAÇÃO AMAZÔNICO ${ }^{1}$
}

\author{
Maria José Aviz Rosário \\ Professora do ICED/UFPA \\ mrosario@ufpa.br \\ Celita Maria Paes de Sousa \\ Professora do ICED/UFPA \\ celtps@hotmail.com \\ Maria de Fátima Matos de Souza \\ Professora do CDI/UFOPA \\ fmatos@ufpa.br
}

\section{RESUMO}

Este artigo reúne elementos para discussão de uma aproximação teórico- metodológica acerca da constituição e organização do Museu da Educação Amazônico como guardião de fontes que registram a história da educação da Amazônia. Parte da tese de que à constituição do museu é uma necessidade imperiosa para a guarda, preservação e reflexão permanente da história e memória da educação da Amazônia. Objetiva disponibilizar a comunidade ligada à pesquisa, à extensão e ensino no campo da História da Educação, elementos iniciais ao debate sobre fontes e materiais amalgamadores de novos conhecimentos à sedimentação em história e historiografia da educação Amazônica, a partir do espaço museológico. Sua estruturação situa o estudo apresentando a temática o objeto e o problema de estudo, evidenciando as principais mediações quando da articulação, elaboração e execução da proposta de constituição do museu. Em sua conclusão preliminar apresentam-se dados analisados que resultam nos primeiros achados da pesquisa, tais como, percalços para a efetivação da ideia em torno da criação do museu, como espaço de referência para a pesquisa em história da Educação da Amazônia e destruição de acervos importantes de instituições escolares, a exemplo do Grupo Escolar Padre Luiz Gonzaga, de Bragança - PA. Os dados mostram que a instituição sofre com a falta de tratamento, organização e acondicionamento adequado de acervos documental, iconográfico, cartográfico, artístico e estatístico e outros materiais importantes do registro de sua trajetória, como os que indicam a sua criação relacionada à articulação da proposta de expansão da educação primária nos anos de 1960; sua constituição em uma das instituições escolares mais importantes de formação do povo bragantino, no Século XX e, por conseguinte da Amazônia; a proposta de um modelo pedagógico, baseado no respeito e disciplina, amor à pátria; o acesso ao ensino primário público; da influência da igreja católica da distribuição de merenda escolar e; da indumentária das professoras. Esses dados iniciais são elementos significativos para se afirmar a necessidade imperiosa da criação do Museu da Educação Amazônico como espaço de produção de novos conhecimentos à área de história da Educação e a história e memória da educação amazônica, em última análise do povo da Amazônia.

Palavras-chave: Museu da educação, acervos e fontes, história da educação 


\title{
AMAZON MUSEUM EDUCATION
}

\begin{abstract}
This article brings together elements for discussion an approximation theoretical and methodological about constitution and organization of the Amazon Museum Education as guardian of sources that record the history of education in the Amazon. Part of the argument that the establishment of the museum is a pressing need for the custody, preservation and reflection permanent of the history and memory of education Amazon. Part of the argument that the constitution of museum is a need mandatory for the custody, preservation and reflection permanent of the history and memory of education of the Amazon. Objective provide the community linked to research, extension and teaching in the field of History of Education; initial elements to debate about sources and materials the sedimentation at history and historiography of education Amazon from museum space. Its structure situate the study presenting the subject, and the object of study problem., evidencing the mediation main when of the articulation, elaboration and execution of the proposal of the constitution of the museum. In its preliminary analysis presents data that result in the early research findings, such as mishaps for the realization of the idea around the creation of the museum as a place of reference for the history of education research in the Amazon and destruction of collections Important educational institutions, such as the School Group Priest Luiz Gonzaga de Bragança - PA. The data show that the institution suffers from a lack of treatment, organization and packaging of adequate documentary collections, iconographic, cartographic, statistical and other artistic materials and important record of his career, as indicating its creation related to the articulation of the proposal expansion of primary education in the 1960s, its constitution in one of the most important educational institutions to train people Bragantine, in the twentieth century and therefore the Amazon, the proposal of a pedagogical model based on respect and discipline, love of homeland; access to primary public influence of the Catholic church, the school and of snack distribution; clothing of the teachers. These initial data are significant elements to affirm the absolute necessity of the creation of the Museum of Education as an area of Amazonian as production of new knowledge to the field of history of education and history of education and memory Amazon ultimately the people of the Amazon.
\end{abstract}

Keywords: museum education, collections and sources, history of education

O Museu da Educação Amazônico é um projeto do Grupo de Estudos e Pesquisa em História e Educação - GEPHE, FAED/ICED/UFPA e do Grupo Estudos e Pesquisas "História, Sociedade, e Educação no Brasil - HISTEDBR - Secção - PA FAED/ICED/UFPA/FE/UNICAMP". Constitui-se numa primeira tentativa de transformar o espaço da Sociedade Paraense de Educação, cedida à UFPA, desde 2000, em Museu da Educação Amazônico, como um lugar de organização, de guarda e preservação da história e memória da educação da Amazônia; destinado à pesquisa, à extensão e ensino na História da Educação com vistas à sedimentação da pesquisa em história e da historiografia da educação Amazônica.

A justificativa para a constituição do museu aponta a dificuldades de se circunscrever à educação amazônica na historiografia nacional principalmente por falta de espaço em que se possam encontrar dados organizados, catalogados, sistematizados e disponibilizados à sociedade e pesquisadores. 
A ideia de criação de um Museu da Educação é antiga ${ }^{2}$ e tem mobilizado um conjunto de pesquisadoras/es de Norte a Sul do Brasil ${ }^{3}$. Essa mobilização tem remetido à ideia da criação de museus educacionais como espaços privilegiados destinados a guarda da história e memória da educação e a produção de novos conhecimentos.

Na UFPA, à medida que a pesquisa no campo da história da educação ganhava corpus, os grupos de pesquisa GEPHE $^{4}$ e HISTEDBR/Secção-PA foram criados e alimentaram o desejo de constituir, no estado do Pará, um museu que pudesse ser o guardião de nossas histórias e memórias educacionais amazônicas. Os produtos dos projetos de pesquisa, Pégasus ${ }^{5}$, Guia de Fontes do Ensino Primário de Belém do Pará, no Século XX: da instrução primária ao ensino fundamental ${ }^{6}$ e Coletânea de Documentos da Educação Imperial (1839 - 1889), foram decisivos para o início do processo de criação, envolvendo articulação entre as instituições envolvidas, composição da equipe de pesquisadores e o acompanhamento jurídico normativo da cessão do espaço.

Em 2009, quando da vinda do coordenador executivo do HISTEDBR, ao Pará para tratar da articulação da história da educação Amazônia à história da educação brasileira, o projeto ganhou institucionalidade ${ }^{7}$.

Outro aspecto potencalizador do processo de criação do museu e que atravessa o trabalho e estudo daqueles que se dedicam a área, é a constante preocupação com o problema da localização de registros organizados da história da memória da educação amazônica, em lugares mais acessíveis e adequados à preservação, a pesquisa, ao ensino e a extensão.

O problema da localização de registros organizados da história da educação amazônica se constitui em um problema que ocasiona, sem dúvida, prejuízos à educação porque dificulta levantamentos mais precisos de fontes históricas em educação, na Região Amazônica, ainda que esta conte compesquisas que apontam um rico acervo; os dados ${ }^{8}$ encontram-se dispersos, fragmentados e sob a guarda de diferentes pessoas, cujo acesso é muito restrito. Isso dificulta a inserção da educação amazônica na historiografia nacional e, consequentemente, a potencialização do seu uso científico.

O que permeia a nossa reflexão é a discussão do sentido mais amplo da contribuição dos museus à educação. Que essencialmente está intimamente relacionado com o problema da preservação do patrimônio e da publicização de nossas heranças culturais".

Em 1992, Clarice Nunes indicava:

A identificação de acervos e documentos de interesse para a pesquisa no Brasil é uma preocupação constante de historiadores, cientistas e estudiosos em geral frente às dificuldades para se obter informações sistematizadas sobre o conteúdo e as condições de acesso a essas fontes. (p. 11)

Em 2009, portanto depois de 17 anos, Ana Palmiro Casemiro, na apresentação do Livro, "A pesquisa e a preservação de Arquivos e fontes, para a educação, cultura e memória, continua alertando".

Há, no campo da História da educação, no Brasil e na Bahia, há muito tempo, a ausência de publicações sobre acervos documentais e fontes primárias, bem como de informações sobre os arquivos em que esses documentos se encontram guardados [...] (p.9).

Revista HISTEDBR On-line, Campinas, n.48, p. 40-49 Dez.2012 - ISSN: 1676-2584 
Em âmbito geral a preocupação com a criação de museus ganhou fôlego com a criação do Instituto Brasileiro de Museus (Ibram), criado pela Lei $\mathrm{n}^{\circ} .11 .906$, de 20 de janeiro de 2009, no âmbito do Ministério da Cultura, como órgão responsável pela implementação democrática e participativa da Política Nacional de Museus (PNM).

$\mathrm{Na}$ Amazônia, no estado do Pará em particular ${ }^{10}$, os museus guardam a herança geral cultural de toda a Amazônia, sem, no entanto, destinar um lugar específico à educação, dificultando sobremaneira o trabalho de identificação e tratamento de fontes na área de história da educação.

A transformação do espaço da Sociedade Paraense de Educação em Museu da Educação Amazônico, além de necessária é uma exigência à pesquisa, a extensão e ao ensino na área de história da educação como contribuição ao desenvolvimento educacional amazônico e nacional. Essa perspectiva corrobora com Chagas (2009, p.17).

A preservação constitui o domínio mais amplo do campo de proteção do patrimônio, dentro do qual estão inseridas as ações de conservação e restauração. As ações de preservação englobam iniciativas de caráter geral, tais como: a pesquisa, a difusão, o acautelamento ou proteção legal por parte do poder público (por exemplo, o registro como bem de interesse público ou o tombamento), a elaboração de políticas, planos, normas e diretrizes diversas, as medidas econômicas voltadas para o financiamento e a manutenção das instituições, entre outras.

Por outro lado, a constituição de espaços apropriados a guarda da história e memória da educação é uma resposta as indagações resultantes das pesquisas empreendidas, pois o estudo isolado em grupos e universidades da Amazônia, tal qual em outros centros não tem dado conta dos inúmeros objetos e materiais.

A busca de um "espaço" que viabilizasse a compreensão, interpretação, discussão e realização da investigação sistemática sobre seus objetos de estudos, suas interpelações e interrogações, que o conhecimento isolado já não dava conta de responder, de fato possibilitaram a implantação do Museu Pedagógico no final do ano de $1999^{11}$.

Esses espaços permitem a interface entre os processos educativos e a museologia que é a ciência que se debruça sobre a relação do homem com seu patrimônio, entendendo patrimônio como aquilo que é reconhecido como herdado de gerações passadas, aquilo que é construído como referencial e mesmo aquilo que é construído para suportar (ser suporte) de uma memória.

A perspectiva de criação do Museu Amazônico, além da preocupação como um espaço de organização, de guarda e preservação da história e memória da educação da Amazônia, destinado à pesquisa, à extensão e ensino na História da Educação com vistas à sedimentação da pesquisa em história e da historiografia da educação Amazônica, considera que essa educação, historicamente se pautou na luta para garantia do direito à educação, tendo se constituído em um elemento decisivo de reorganização socioeducacional e que em seu rastro encontram-se vestígios indeléveis das lutas sociais e que portanto apresentam diversos entendimentos da produção do conhecimento, logo o seu acervo educacional, traz consigo as marcas desse tempo histórico em sua memória.

As instituições escolares geram importantes coleções de documentos e registros educacionais. Contudo, ainda pode-se dizer que esses documentos têm sido pouco utilizados como fonte histórica. Isto significa que boa parte dos métodos empregados na pesquisa em educação reconhece pouco valor histórico dos 
documentos que revelam as "tradições e regularidades institucionais sedimentadas ao longo do tempo ${ }^{12}$.

Neste sentido, a perspectiva da ampliação do universo documental, a diversificação do conceito de documento ${ }^{13}$, seja eles orais ou escritos, implica na valorização de outros suportes não convencionais e, consequentemente a potencialização de seu uso científico.

O processo de discussão alcançado pela ciência da História, pouco a pouco foi sendo apropriado pela História da Educação e a área foi instaurando questões complexas e singulares sobre o seu objeto - a educação e o seu "alargamento objetual", bem como, um importante debate sobre o método, o recorte espacal e o exercício da heurística para encontrar as fontes, possibilitando uma revisão vigorosa sobre a historiografia da educação brasileira ${ }^{14}$.

Para compreender melhor o processo de constituição da Educação da Amazônia faz necessário ampliar conhecimentos sobre a história de sua produção. Essa tarefa demanda organização, catalogação das fontes históricas e outros materiais referentes aos diversos processos, porque ainda que as pesquisas realizadas apontem um legado, as fontes históricas ${ }^{15}$ encontram-se dispersas, fragmentadas e sob a guarda de diferentes pessoas, cujo acesso é muito restrito.

A questão da falta de tratamento ao estudo local e regional da história da educação constitui-se num problemática educacional em todo Brasil, sobretudo quando a questão é remetida aos Cursos de Licenciaturas.

[...] nos cursos de pedagogia e licenciaturas, em geral, pouco se discutiu ou discute-se sobre o valor histórico do documento e as suas concepções. Se os diretores, secretários de educação, professores, alunos, etc., em larga medida, apenas manuseiam o documento como recurso momentâneo e não tem conhecimento da importância da organização e da guarda dessas fontes para o estudo da história da educação, como desenvolver um processo de valorização da memória educacional? Mesmo nos cursos de pós-graduação ou em outros cursos de formação acadêmica é pouco discutida a necessidade do uso do recurso heurística, ou seja, da busca do documento como recurso essencial para o estudo da história da educaçãa ${ }^{16}$.

Apesar das dificuldades, incursões à História da Educação da Amazônia, apontadas nos relatórios de pesquisas, dissertações e teses, indicam que essa história constitui-se em pedaços de pedaços da história da educação brasileira. História que revela exigências dos períodos históricos, a movimentação das forças sociais que compuseram a sociedade, a partir de seus interesses, de suas condições materiais e opções políticoideológicas, produziram debates intensos numa tentativa de orientar os rumos das políticas sociais, incluindo as do ensino.

A produção do conhecimento na área da história da educação, na Amazônia revela-se singular e em seu processo de construção foi demonstrando um número considerável de fontes históricas indicando aos pesquisadores o caminho do museu em que o acervo riquíssimo possa ser guardado, organizado, catologado e sistematizado e resgatado historicamente.

O Museu da Educação Amazônico, é de relevância para a educação da Amazônia, que a despeito de inúmeros esforços, ainda carece de trabalhos que possam dar conta, do ponto de vista científico, de como foram constituídas as bases da de sua educação e se 
apresenta como perspectiva de contribuir para a inserção da história da educação da região na historiografia educacional e na pesquisa educacional.

Por outro lado, a organização do Museu da Educação Amazônico, contribuirá para minimizar problemas de acesso às informações, particularmente no que tange a dispersão documental, destruição e alienação de documentos e deverá estimular os detentores de acervos a organizar e preservar seus documentos sob condições técnicas adequadas e, sobretudo abertos à consulta.(cf. Nunes, 1992).

O Museu da Educação Amazônico pretende se constituir em um espaço de produção de conhecimentos, reflexões, pesquisa e produção de saberes sobre questões relacionadas à trajetória e história da educação da Amazônia, a partir da catalogação de fontes documentais primárias, cartográfica, iconográficas, fílmicas, sonoras, literárias, estatísticas, sejam elas orais ou escritas, no sentido de possibilitar diferentes olhares sobre o mesmo objeto.

O projeto de criação do Museu da Educação Amazônico, prevê cinco fases articuladas e que ao mesmo tempo se constituem em sujeito e objeto da história da educação da Amazônia.

A primeira fase -tratará do acervo do professor Antonio Moreira Gomes e do espaço e acervo Sociedade Paraense de Educação, sob tutela da UFPA. Esta etapa se converterá num guarda chuva que abrigará as demais fases e instituirá de fato e de direito o museu.

Segunda fase - dedicar - se - á com projetos próprios ao levantamento, higienização, organização, catalogação, sistematização e digitalização dos seguintes acervos. Em Belém, acervos do Colégio Estadual Paes de Carvalho e Instituto de Educação do Pará - IEP pertencentes à Secretária de Estado de Educação - SEDUC e acervo do Colégio Gentil Bittencourt, pertencente à Congregação Filhas de Santana; em Bragança, acervo dos Grupos Escolares Monsenhor Mâncio Ribeiro e Padre Luiz Gonzaga, pertencentes à Secretária de Estado de Educação - SEDUC; em Santarém, acervo do Colégio Dom Amando; e em Castanhal, acervo da antiga Escola Agrotécnica de Castanhal, pertencente ao IFPA. Esta fase será também, destinadas à aquisição de outros materiais referentes ao diversos processos educacionais da região, como iconográficas, audiovisual, etc. para a composição do museu.

A terceira fase, destinada à organização museológica do espaço da Sociedade Paraense de Educação, situada à avenida Almirante, cedida desde 2002, à UFPA, a qual receberá os acervos tratados, e de outros materiais referentes ao diversos processos educacionais da região, assim como a construção do plano de ocupação dos espaços (salas de exposição, reserva técnica, salas administrativas, espaço de ação educativa e cultural, espaços de serviços, espaços de circulação, sala de segurança, outros espaços).

A quarta fase, encetará a produção da Documentação para a criação de museus como, registro da criação do museu;estatuto jurídico e sua natureza administrativa; regimento interno;organograma;Plano Museológico;Identificação de percursos e roteiros no território de atuação do museu ${ }^{17}$.

A quinta fase será a abertura do espaço da Sociedade Paraense de Educação como o Museu da Educação Amazônico a comunidade, constituindo-se em um espaço pesquisadores, poderes públicos constituídos (órgãos de administração de ensino), para os movimentos sociais organizados (sindicatos, associações, centros comunitários, etc.), ONG, e sociedade de modo geral e referência a produção de conhecimentos, reflexões, pesquisa e debates sobre questões relacionadas à trajetória e história da educação, a partir da catalogação de fontes documentais primárias, cartográficas, iconográficas, fílmicas, sonoras, literárias, estatísticas, sejam elas orais ou escritas, no sentido de possibilitar 
diferentes olhares sobre o mesmo objeto e leituras interdisciplinares. Indicando, inclusive, que há lugar para a transdisciplinaridade, no ambiente acadêmico ${ }^{18}$.

Alguns achados da pesquisa.

Durante o processo de execução do projeto de criação do Museu da Educação Amazônico, dados relevantes sobre a história da educação foram sendo revelados.

Em termos institucionais, a burocracia excessiva, é um dos fatores impeditivos para liberação de espaços, especialmente os históricos destinados a instituições de ensino, pesquisa e extensão. À UFPA foi doado, há mais de 12 anos, o acervo do professor Antonio Gomes Moreira $\mathrm{Jr}^{19}$ juntamentecom espaço da Sociedade Paraense de Educação ${ }^{20}$, futuro espaço do museu, entretanto ainda não foi possível a posse, por causa das questões normativo/jurídicas.

Em se tratando dos acervos das instituições escolares, constatamos que uma boa parte foi extraviada, como é o caso de parte do acervo do Grupo Escolar Padre Luiz Gonzaga, de Bragança-PA., ao qual foi realizada uma análise preliminar.

A instituição foi fundada em 19 de março de $1962^{21}$, encontra-se em pleno jubileu de ouro, porém sua história precisa ser recuperada, já que parte de sua documentação, perdeu-se em seus porões (banheiros). O levantamento foi realizado a partir de estudo exploratório ao Projeto Político Pedagógico, de fotografias e documentos de arquivos pessoais e de visitas ao prédio, e da escuta da segunda diretora que passou 20 anos no cargo, da segunda secretária e duas professoras da primeira geração.

Os dados indicamo grupo como importante instrumento de articulação da proposta de expansão da educação primária nos anos de 1960, já que sua criação, em 1962, em uma casa alugada, segunda a diretora ouvida, atendia a reivindicação da nova população da cidade, ou seja, os agricultores e pescadores dos campos de cima e de baixo ${ }^{22}$, das praias e colônias, foram empurrados para os arrabaldes e lá chegando, exigiam do governo municipal, escolas para seus filhos. Nesse período, Paulo Freire 'interpretava a sociedade brasileira dos anos de 1960 como processo de trânsito de uma sociedade fechada para uma sociedade aberta' (SAVIANI, 2008). Nesse sentido, 'os setores esquecidos do campo verdadeiros órfãos da política populista- começaram a se mobilizar. O pano de fundo dessa mobilização parece se encontrar nas grandes mudanças estruturais ocorridas no Brasil entre 1950 e 1964, caracterizadas pelo crescimento urbano' (BÓRIS, 2002).

Além desse atendimento, a escola também era tida como modelo pedagógico. A diretora, a secretária e as professoras ouvidas destacam pontos importantes e fortes de educação; a) o respeito e a disciplina às crianças e adolescentes, "todos tinham respeito por nós, às regras eram aceitas de bom grado, o horário era cumprido. Não é como hoje, alunos sem limites, intolerantes a qualquer tipo de regra social", relata uma professora. Esse entendimento pode ser derivado da emergência da concepção produtiva em educação que 'adquiriu força impositiva ao ser incorporada a legislação na forma dos princípios da racionalidade, eficiência e produtividade [...]' (SAVIANI, 2008); b) o amor à pátria mostrado por meio do cântico do Hino Nacional. "naquela época todo mundo sabia cantar o hino nacional, hoje se perdeu o respeito, por este símbolo da pátria, ressalta a secretária; c) acesso ao ensino, 'não deixava nenhuma criança sem estudar, dizia: professora coloque mais um em sua sala', orgulha a diretora.'Porém quando a superlotação alcançou todos os limites, foi necessário procurar alternativas, desse modo, foi feita uma negociação com escolaEscolaCenecistaProfessor Paixão e os foram transferidos para lá, sem prejuízo do ano letivo', diz a secretária; d) influência da igreja católica. A catequese, do grupo, era de responsabilidade da paróquia que por intermédio de um sacerdote, iniciava os alunos nos ritos da igreja, tendo como ápice a realização da primeira comunhão, onde pelas fotografias, observa-se a divisão de classe, os pobres de uniforme e no final da fila e os 
"ricos" vestidos a rigor e perfilavam-se no início; d) a merenda escolar, composta de leite e mingau que inicialmente era proveniente da Cáritas Brasileira e distribuído aos alunos e mais tarde por doações de pessoas do bairro, também denominado de Padre Luiz; e e) indumentária das professoras, blusa branca e saia preta. 'Era bonito de ver as professoras do Padre Luiz, com seus uniformes e orgulhosas da profissão, nós nos encontrávamos, pois morávamos quase todas no arredores da escola, quadras A, B, C e D', diz uma professora. A análise preliminar, permite afirmar, no grupo escolar Padre luiz Gonzaga vestígios de uma educação que acompanhou as mudanças ocorridas na sociedade brasileira e bragantina, às vezes sem se dar conta e outras nem sempre. 'passamos do ensino velho (referindo-se ao ensino primário) para o ensino novo (ensino de primeiro), sem muitos traumas, foi tudo normal, como mandava a SEDUC, por meio do Seu Landolfo Alves (espécie de secretário de educação)', afirma a secretária.

O grupo escolar Padre Luiz Gonzaga, é uma das instituições escolares mais importantes de formação do povo bragantino, no Século XX e por conseguinte da Amazônia.

Esses dados iniciais são elementos significativos para se afirmar a necessidade imperiosa do Museu da Educação Amazônico.

\section{Referências}

BITTENCOURT, Ana Pamira. A Pesquisa e a Preservação de Arquivos e Fontes para a Educação, Cultura e Memória. São Paulo - Campinas: Editora Alínea e Átomo, 2009

CHAGAS, Mário de Souza e NASCIMENTO JUNIOR, José do(organizadores).Subsídios para a criação de Museus Municipais Rio de Janeiro, RJ: Ministério da Cultura/Instituto Brasileiro de Museus e Centros Culturais/Departamentode Processos Museais, 2009. 40p.ISBN 978-85-7334-125-6

CENTRO DE PESQUISA E DOCUMENTAÇÃO DA História CONTEMPORÂNEA BRASILEIRA - CPDOC. Guia brasileiro de fontes para a história da África, da escravidão negra e do negro na sociedade atual. Fundação Getúlio Vargas

CENTRO DE PESQUISA E DOCUMENTAÇÃO DA História CONTEMPORÂNEA BRASILEIRA - CPDOC. Guiade acervos bibliográficos e arquivistas de ex-presidentes da República. Fundação Getúlio Vargas

BÓRIS, Fausto. História do Brasil. São Paulo: Editora da Universidade de São Paulo, 2002

HISTEDBR. Cartografia das fontes documentais para a história da Educação Maranhense no período imperial. HISTEDBR - Maranhão

LE GOFF.J. História e Memória. Campinas São Paulo: Ed. UNICAMP, 1992.

MAGALHÃES, Lívia Diana R. Museu pedagógico:o professor de catalogação das fontes documentais e escolares em Vitória da Conquista.http://www.histedbr.fae.unicamp.br/navegando/artigos_frames/artigo_058.html. Acesso em 8/04/11, às 10:00h. 
NUNES, Clarice. Guia preliminar de fontes para a história da educação. Brasília: INEP, 1992.

ROSÁRIO, Maria José Aviz.A organização da educação no Município de Belém - PA, de 1937 a 1945. Piracicaba-SP: Dissertação (D). Universidade Metodista de Piracicaba UNIMEP, 1998.

\section{ROSÁRIO, Maria José Aviz. O PCB E A ORGANIZAÇÃo DO ENSINO PÚBLICO PRIMÁRIO DE BELÉM DO PARÁ (1945 a 1964). São Carlos - SP, Tese (T). Universidade Federal de São Carlos - UFSCAR, 2006}

SAVIANI, Dermeval. O local e o nacional na historiografia da educação brasileira. São Paulo - Campinas: Editora Alínea, 2008

\footnotetext{
1 Artigo apresentado no IX Seminário Nacional do HISTEDBR, realizado na Universidade Federal da Paraíba, em João Pessoa, entre 31 de julho e 3 de agosto de 2012.
}

${ }^{2}$ Experiências indicativas da necessidade do Museu. Em 1989, no magistério de nível médio, com a disciplina Estrutura e Funcionamento do ensino de Primeiro Grau, mostrou incialmente, a falta de dados organizados, catalogados e sistematizados sobre o ensino público do município de Belém-PA e no magistério superior, a partir de 1992, com a disciplina Estrutura e Funcionamento do Ensino de $1^{\circ}$ e $2^{\circ}$ Graus exigia pesquisa como suporte para as discussões a respeito do sistema de ensino municipal, levou a dois trabalhos: Ensaio (1995) cuja base era a reconstrução da organização do ensino de modo geral e, com o projeto (1996) de ensino intitulado: "A Organização, o Funcionamento e Estrutura do Ensino Municipal de Belém, de 1930 a 1961", vinculado a Pró-Reitoria de Ensino de Graduação da UFPA. Na Pós-Graduação, nos cursos de mestrado com a procura de dados para a composição da dissertação, intitulada: "A organização do ensino público de Belém-PA, de 1937 a 1945”, defendida em 1998, na Universidade Metodista de Piracicaba UNIMEP e doutorado também a procura de dados para tese, “O PCB e a organização do ensino público primário de Belém do Pará (1945 - 1964)”, defendida em 2006, na Universidade Federal de São Carlos UFSCAR.

${ }^{3}$ Entre os estudos pode-se citar: O guia brasileiro de fontes para a história da África, da escravidão negra e do negro na sociedade atual e o guia de acervos bibliográficos e arquivistas de ex-presidentes da República, vinculados ao Centro de Pesquisa e Documentação da História Contemporânea Brasileira - CPDOC. In Nunes, 1992; As diversas pesquisas vinculadas ao Grupo de Estudos e Pesquisas "História, sociedade e educação no Brasil-HISTEDBR, vinculado a Faculdade de Educação da UNICAMP; Cartografia das fontes documentais para a história da educação Maranhense no período imperial, vinculado ao Grupo História, Sociedade e Educação no Brasil - HISTED-Maranhão e Grupo História, Sociedade e Educação no Brasil HISTED-São Carlos.

${ }^{4}$ Uma das metas do GEPHE consiste na criação do museu da educação, em 2012.

${ }^{5}$ Sub projeto de pesquisa (2001) intitulado: "Levantamento de fontes sobre a Organização do Ensino no Município de Belém - PA., nas décadas de 70, 80 e 90.” PROINT - UFPA. ${ }^{6}$ Projeto de 2008 a 2009, relatório transformado em uma publicação que se encontra no prelo Editora Alínea.
ISBN 978-85-7516-567-6

${ }^{7} \mathrm{Na}$ ocasião foi firmado acordo verbal entre o reitor da UFPA, professor Dr. Carlos de Almeida Maneschy e o HISTEDBR para transformar o espaço da Sociedade Paraense de Educação em um Museu da Educação. A UFPA trataria da questão jurídica que envolve a cessão do espaço e o HISTEDBR da articulação e projeto do museu.

${ }^{8}$ Em 1931, ao seguir o recém-criado Regimento do Ensino Primário do Estado do Pará, Belém reorganizou seu ensino. O mesmo ocorreu em 1943 com outra reformulação no Regimento do Ensino Primário do Estado do Pará. Neste, a base foi pautada nos moldes modernos da Escola Ativa.(1998).

${ }^{9}$ Pasos. Revista de turismo e patrimônio cultural. www.pasosonline.org. 
${ }^{10}$ Entre os museus do Pará pode-se destacar: Arquivo Público do Pará. Travessa Campos Sales, 273 -

Campina, Belém - PA., Biblioteca Pública Arthur Vianna - CENTUR, Biblioteca Municipal Avertano Rocha -Icoaraci, Museu da Universidade Federal do Pará.

${ }^{11}$ Magalhães, Lívia Diana Rocha. O “olhar” do museu pedagógico da Região Sudoeste da Bahia. Anais do VIII Seminário Nacional do HISTEDBR, 2009.

${ }^{12}$ MAGALHÃES, Lívia Diana R. Museu pedagógico:o professor de catalogação das fontes documentais e escolares em $\quad$ Vitória da Conquista.http://www.histedbr.fae.unicamp.br/navegando/artigos frames/artigo_058.html. Acesso em 30/03/11, às 19:50h.

${ }^{13}$ Sobre conceito de documento, consultar: LE GOFF (2000)

${ }^{14}$ MAGALHÃES, Lívia Diana R. Museu pedagógico:o professor de catalogação das fontes documentais e escolares em Vitória da Conquista.http://www.histedbr.fae.unicamp.br/navegando/artigos_frames/artigo_058.html. Acesso em 30/03/11, às 19:59h.

${ }^{15}$ De 1951 a 1961, o Executivo Municipal criou mais de 30 escolas. ROSÁRIO (1998).

${ }^{16}$ MAGALHÃES, Lívia Diana R. Museu pedagógico:o professor de catalogação das fontes documentais e escolares em Vitória da Conquista.http://www.histedbr.fae.unicamp.br/navegando/artigos_frames/artigo_058.html. Acesso em 30/03/11, às 20:14h.

${ }^{17}$ Essas recomendações encontram-se em Chagas, 2009.

${ }^{18}$ MAGALHÃES, Lívia Diana R. Museu pedagógico:o professor de catalogação das fontes documentais e escolares em Vitória da Conquista.http://www.histedbr.fae.unicamp.br/navegando/artigos_frames/artigo_058.html. Acesso em 8/04/11, às 10:00h.

${ }^{19}$ Foi Fundador da Faculdade de Filosofia Ciências e Letras, da UFPA, do Centro de Educação, da UFPA, foi por inúmeras vezes presidente do Conselho Estadual de Educação do Pará, professor da UFPA e UFRA e presidente da Sociedade Paraense de Educação.

${ }^{20}$ O Espaço é composto de 02 apartamentos e uma sala (auditório) com hall. Sito a Avenida Almirante Barroso, bairro do Marco da Légua em Belém - PA.

${ }^{21}$ Ver comemoração do jubileu de ouro, no blog: padreluizgonzaga.blogspot.com.br/

${ }^{22} \mathrm{O}$ município de Bragança, á época, contava com dois lugares, campos de cima e campos de baixo, semelhantes ao campos do Arquipélago do Marajó

Recebido em novembro/2012

Aprovado em dezembro/2012 